\title{
Development of requirements for the BIM model of the Arctic port facilities exploitation
}

\author{
Pavel Garibin ${ }^{1}$, and Evgeniy Ol'khovik ${ }^{1, *}$ \\ ${ }^{1}$ Admiral Makarov State University of Maritime and Inland Shipping, 198035 Dvinskaya 5/7, Saint \\ Petersburg, Russia
}

\begin{abstract}
The development of information modeling technologies for construction offers new tasks to develop operational models for facilities, which are locate in most difficult conditions, here an important example is the marine Arctic ports. To build a life cycle model, reliable long-time information about hydrometeorological conditions for the selected port facility is needed. It also requires accurate data on the design and past loads. We offer the basic methods for obtaining the initial data for operation BIM model subject to the technical and design documentation are absent, what is a common practice for old facilities. The main theses for development of information BIM model for a marine port's facilities exploitation in the Arctic are proposed in this paper. At the initial stage of description of the structure life cycle, it is necessary to develop an electronic passport of the facility that would contain the basic geometric characteristics of the structures elements, the information about the applied materials and their physical and mechanical properties, coordinates of the plan and deformation geodetic network in the digital format. At the next stage, it is necessary to provide automated monitoring for measuring the main parameters of loads, deformations and climatic conditions, which in combination ensure the safety of the port's structures.
\end{abstract}

\section{Introduction}

Marine geotechnical structures of Arctic ports during operation are exposed to intensive destructive processes, which are caused by negative factors of anthropogenic nature and aggressive environmental impact. The location areas of the ports of the Northern Sea Route are characterized by special conditions: it is the Arctic climatic zone, where the duration of the ice period is 8 months. Designing of the maritime Arctic ports is a task that requires a large number of engineering surveys, technical calculations and physical simulation.

Until recently, the efforts of many countries were directed only at elimination of the disasters consequences, but the increasing of catastrophic events number and detriment related with it make these efforts less effective and put forward the forecasting and prevention

\footnotetext{
* Corresponding author: olhovikeo@gumrf.ru
} 
of catastrophes as a new priority task. The introduction of information support technologies of the life cycle of potentially dangerous building structures will allow timely warn the critical destruction and man-made accidents.

Currently, BIM technologies for description of the life cycle of building structures mainly spread to facilities of industrial and civil constructing [1], for transport infrastructure facilities such technologies have not been developed yet. The issue of information models of the port facilities exploitation has not been studied yet, although it is the most relevant.

The development of main requirements to the information BIM model for the exploitation of port geotechnical structures in the Arctic is considered at that paper. The development of an electronic passport of the facility in the case when the project constructional documentation is missing or when it cannot be digitized is of particular interest. In this case, it is necessary to develop additional measures that would allow to restore the technical plan of design and calculation of the structural elements strength [2]. Also, for cases when the previous life cycle of loading (operation under load) of the berthing facility is unknown, we cannot objectively assess the residual constructive strength of the structures. Such a deficit of information can be restored using special methods [3] by simulation of actual loads [4] or comparison them with analogues. In [5], the authors propose the use of information reengineering to construct a model of facility exploitation, but they note the complexity of integration solutions.

\section{Methods and materials}

The truthful perennial information (factual data) about the hydrometeorological conditions for the selected port facility is necessary to formalize the operational BIM model. The climatic conditions of the Arctic territories are due to the uneven receipt of solar radiation during the year, intense atmospheric circulation and the proximity of the cold seas (Kara, Laptev, East Siberian and Chukchi). The absence of hydrometeorological stations in the Arctic or their location at a great distance from each other does not allow obtaining objective information about the climatic conditions. To solve this problem, it is most optimal to install your own equipment for measurement of fluctuations in daily temperature, duration of daylight, humidity, direction and strength of the wind. All collected data should be stored in a spreadsheet (database) and included to the information model for the port facility exploitation. The flow of the high-water Rivers of Siberia, as well as waters coming from the Atlantic and Pacific Oceans exert significant influence. Fluctuations of water levels are mainly determined by afflux-reflux phenomena, the magnitude of which significantly exceeds the fluctuations of the water level as a result of high tides and low tides. The shores of the Arctic seas of Russia are mostly low. The exception is Novaya Zemlya Island, as well as the Taimyr Peninsula and the Chukchi Peninsula. Soils of the banks are represented by sands, silt, pebbles, gravel, stone and rock. Accounting of the hydrological mode can also be performed by own forces. For this purpose it is necessary to equip a stationary water-meter post in such a way that the water level is tied to a high-altitude coordinate system (Baltic Normal Height System, 1977). Additionally it is necessary to measure the water temperature at the surface and at the bottom, and in winter period it is necessary to measure ice thickness. In addition, the height of the snow cover can be measured. All collected data on the hydrological mode of the water area should also be stored electronically for accounting in the information model of the port facility exploitation.

A cold and long winter with a low height of snow cover causes deep freezing of soils and grounds, which leads to the formation of permafrost. Most of the Arctic port facilities are located in the permafrost zone. Thickness of the permafrost in the polar circle ranges from $400-450 \mathrm{~m}$ to $250-300 \mathrm{~m}$. Its breach is very dangerous and can lead to the destruction of the constructional part of the berths. It is necessary to install thermocouple kits to permanently 
monitor the state of permafrost on the territory of the hydraulic structure. The information from the thermocouple kits must also be constantly collected in the information model of exploitation. The number of thermocouple kits and the location of their installation is a separate task, which must be solved by the results of engineering surveys.

Also, the technical condition of Arctic ports is affected by natural phenomena, whose observations and measurements do not have standard solutions yet. For example, the turbulence in the Arctic seas is determined not only by the speed and direction of the wind, but also by the presence of ice and the depth of the sea. There is a rare and dangerous phenomenon in the coastal zone of the Chukchi Sea - the "glacial storm". The essence of the phenomenon is as follows: a strip of finely broken ice with a width of about 2 miles with a cohesion of 2 to 6 points blocks the coast. Waves wash up ice to the shore, rallying it to 10 points, while the width of the ice strip decreases to 3 cable. When approaching the shore, waves are destroyed, surf occurs, while waves up to $3 \mathrm{~m}$ high lift the clumps of ice and crush them down on the shore, destroying the coastal structures [6]. One of the options of constant observation for similar natural phenomena in the Arctic is the analysis of space stereoscopic snapshots, but such technologies are only being developed.

The general glacial mode of the Arctic seas is characterized by a decrease in the ice cover cohesion, which keeps most of the year. The largest seasonal and interannual variations in the thickness and area of the ice cover are noted in the region of $70-80^{\circ}$ latitude. Observations of glacial situation can be performed on the basis of existing forecasts, operational space shooting, microwave radiometry data. All these technologies are available today, their cost is constantly decreasing. According to our data, in 2018 the cost of archived processed satellite snapshots fell to $\$ 10$ per sq. km and their quality is constantly increasing. In the future such snapshots can also be included in the information model of the port facility as separate data. Ice situation maps are available with a resolution of $250-500 \mathrm{~m}$.

Berths in the north and arctic seas on the unfrozen water areas in the initial period of their creation were built of wood $[6,7]$. Later in the ports of the Arctic the berths of metal and reinforced concrete tongue (jetty, shells), as well as from massive masonry and with use of ice as a building material were being constructed. Taking into account the short period of the year with positive temperatures, it is currently recommended to use the berths from prefabricated steel shells of large diameter (9-15 m). The mass of one shell, for example, with a diameter of $10 \mathrm{~m}$ and a height of $12 \mathrm{~m}$, is 30 tons, wherein a specific metal consumption is 2-4 tons per running meter of the berth [7]. According to V.D. Kostyukov [8] in the Arctic conditions, the following types of berthing facilities are mainly used:

- cellular constructions from steel tongue;

- pile structures with use of steel tubular piles and frameworks of pipes;

- structures of gravitational type from giant massifs;

- anchored walls of steel tongue and wooden piles;

- glacial berths.

Dotty berths for tankers mooring will play a special role for the Arctic in connection with the increase in traffic volumes of liquid hydrocarbon. The peculiarity of building of such a berth is great depths and remoteness from the shore. In these conditions it is expedient to build it from giant massifs. Herewith both single arrays and individual sections-arrays can be used for the composition on a place of dotty terminal.

At present, the existing thematic BIM databases can be used for the information description of applied constructions and materials in Arctic ports. Complexity is caused only by the determination of the physics and mechanical properties of materials that are already in operation for a long time. For this we propose to apply selective instrumental measurements of residual strength and thickness. These data will also be included in the information model of the facility. The main direction of port facilities monitoring in the Arctic is deformation monitoring of the main constructions elements. In [9-12] we proposed 
equipment and techniques of continuous deformation monitoring based on the application of MEMS-sensors and ARM-microcontrollers.

\section{Results}

A distinctive feature of the mooring hydraulic facilities is that they are located on the border of interaction of two different physical environments ("water" and "dry land") with each other. Underwater part of the berth is affected by ground and surface water. The foundation of this part of facilities during building experiences an external impact, leading to a deviation from the existing natural balance due to the redistribution of the forces of changing of the boundaries of different layers, their power (thickness) and orientation. Implementation of engineering and geological researches in this part of the facilities is complicated by the absence of visual contact with the surface of the foundation and the complexity in determination of the strength characteristics of the soil using standard methods and apparatus.

Therefore, the BIM model of facility exploitation should contain not only information about the construction itself, but also calculated schemes of interaction with the external environment. The first part of this task we solve by data collecting about the local deformations and hydrometeorological conditions. The second part of the task should contain the possibility of automatic calculations with the issuance of recommendations for future monitoring and exploitation mode. Mandatory presence of the technical condition monitoring service $[13,14]$ should be included in the composition of operations on exploitation of port engineering facilities, herewith the main measured indicators should be automatically added in the BIM model as information about the facility life cycle [15]. In addition, the experience of studying the separate characteristics of the environment should be considered [16], this is necessary for planning operational and maintenance work [17].

The facility does not allow emergency situations, it does not prematurely exhaust the temporal resource of exploitation, it does not require the costly capital repair works at proper maintenance in accordance with the accepted methods [13, 14], which envisage timely elimination of defects and damages. In this regard, the inspection of the facilities technical condition, focused on the damages detection and technical condition diagnostics, is a prerequisite for ensuring their operability and safety.

Glacial loads accounting, which can be issued in the form of various calculation models [18], for which periodic checks are necessary to carry out is an important factor for Arctic port facilities that determines the conditions for safe operation. Despite the complexity of such calculations, they can be included in the information BIM model of the facility, where they are performed taking into account the updated data. A characteristic feature of the natural and technical system "mooring facility - foundation - water environment" is the significantly different information support of its subsystems: the largest - at the berth superstructure, at the pond, lesser - at the underground part of the facility, even less - at the foundation. This requires the application of methods of the structural theory of reliability with possible different models of uncertainty at the subsystems level [19] (for a hydraulic facility - a deterministic or probabilistic approach to reliability assessment, for a foundation - probabilistic or feasible approach, etc.) with the aim of the most complete and rational use of available information and the maximum narrowing of the evaluation interval of system reliability in general.

\section{Discussion}

If we do not take operational measures with regard to the exploitation of potentially dangerous objects, then the number of man-made disasters will increase. First of all, this 
refers to the morally obsolete and physically worn port facilities and structures that need to be modernized [20]. In this section, we would like to discuss a number of issues of the BIM model development for the mooring facilities exploitation, which have not found yet an independent solution. The engineering-geological works in the coastal part of the port facilities is complicated by the anisotropy of the dynamic loads distribution, the impact of the aquatic environment, value of which varies depending on the season, times of day, and other parameters. The saturation of the soil of this part of the facility by the water largely changes due to the fact that unloading of groundwater with heightened traveling speeds occurs precisely here. Due to the presence of organic residues in a coastal zone of burial (in marshes, oxbows, lakes, coastal screes) wastewaters distribution within populated localities leads to the microorganisms evolution and changes in the floating properties of coastal primings. However, all these factors require complex equipment for long-term measurements. Carrying out such measurements using non-destructive monitoring methods is still impossible or very expensive. Therefore, we consider that it is not advisable to include them in the BIM model for exploitation, except for the cases of practical necessity.

The noted features of the geological structure of the territories where various port hydraulic facilities can be constructed show the necessity to carry out a number of measures aimed at geological risks reducing, the leading position among which takes the constantly acting control of geochemical, hydrogeological and engineering-geological characteristics. Monitoring of primings condition, groundwaters and the nature of facilities deformations will allow to ensure their safety and the conditions for safe operation.

The existing experience in the construction and operation of terminals for LNG shipment [21] on tankers with a DWT more than 200 thousand tons using BIM technologies can be successfully transferred to the Arctic region, for example, in the Ob Bay, where engineering surveys and the design of new hydraulic structures are carrying out now. Herewith it is necessary to take into account the existing design experience [22], which has a positive result. In paper [23] the questions about of economic calculations of the cost of works for monitoring the technical condition of quay walls are considered. A similar method can be included in the BIM model for automated planning the maintenance costs.

\section{Conclusion}

The main theses for the development of the information BIM model for the sea port facilities exploitation in the Arctic are proposed in the paper. At the initial stage of the description of the structure life cycle, it is necessary to develop an electronic passport of the facility that would contain the basic geometric characteristics of the structures elements, the information about the applied materials and their physical and mechanical properties, the coordinates of the plan and deformation geodetic network in the digital format. In addition, in the next stages it is necessary to supplement the electronic passport with the information on the berth's equipping with means of automated monitoring of the environment and deformations, all data should be collected in an automated mode for future analysis. At the last stage, it is necessary to generate the computational models for implementation of periodic inspections of the hydraulic facility exploitation conditions.

The developed BIM model will allow to prepare a plan for the following surveys and repairs objectively. All operational and planned observations of the technical condition will be recorded in the electronic passport in a uniform form, which will allow to describe the facility life cycle with high reliability, avoid excessive and inefficient operations.

\section{References}


1. R. Volk, J. Stengel, F. Schultmann, Automation in construction 38, 109-127 (2014)

2. D.D. Perhavec, A. Tibaut, Journal of Civil Engineering and Architecture Research 1.4, 251-259 (2014)

3. E. Corry, M. Keane, J. O’Donnell, A. Costa, IBPSA Building Simulation 1422-1429 (2011)

4. A.M. Yudelevich, Hydrotechnical construction 8, 122-129 (2017)

5. E. Gusakova, E3S Web of Conferences 33, 03063 (2018) doi:10.1051/e3sconf/20183303063

6. G. N. Evtushenko, M. A. Kolosov, A.V. Silin, R. M. Narbut, The Northern ports of Russia (Gidrometeoizdat, SPb, 2006)

7. E.I. Suslikov, V.I. Morozov, B.A. Pinegin, Port hydraulic engineering construction in the Ob-Irtysh basin. Main design solutions of hydraulic structures and areas for their improvement (OJSC "Sibrechproekt", Novosibirsk, 2002)

8. V.D. Kostyukov, Port hydraulic structures 108-159 (Moscow, 1986)

9. P.A. Garibin, E.O. Ol'khovik, News of Higher Educational Institutions, Construction 2(674), 58-72 (2015)

10. P.A. Garibin, E.O. Ol'khovik, Vestnik of the Siberian State University of Geosystems and Technologies (SSUGT) 2(34), 55-64 (2016)

11. A.Y. Oleynik, A.V. Makshanov, V.E. Marley, Vestnik Gosudarstvennogo universiteta morskogo i rechnogo flota imeni admirala S.O. Makarova 1(29), 215-222 (2015)

12. P.A. Garibin, E.O. Ol'khovik, Proc. of the Int. Conf. on Port and Ocean Engineering Under Arctic Conditions (POAC) (2017)

13. Russian State Standard RD 31.3.3-97

14. PIANC. Inspection, Maintenance and Repair of Maritime Structures Exposed to Material Degradation Caused by a Salt Water Environment (Report of Working Group 17 - 2004 of the Maritime Navigation Commission, 2004)

15. PIANC. Life Cycle Management of Port Structures. General Principles (Report of Working Group No.31 of the Permanent Technical Committee II, 1998)

16. Recommendations of the Committee for Waterfront Structures Harbours and Waterways (EAU, Ernst \& Sohn, 2006)

17. PIANC. Maintenance and Renovation of Navigation Infrastructure (Report of Working Group 25 of the Inland Navigation Commission, 2006)

18. A.T. Becker, Probabilistic characteristics of ice loads on the continental shelf structures (Dalnauka, Vladivostok, 2004)

19. V.A. Pogodin, V.S. Korovkin, K.N. Shkinek, Yu.N. Fomin, Hydrotechnical constructions of sea ports. The textbook (Publishing house "LAN"', St. Petersburg, 2014)

20. K.N. Shkinek, T.V. Filipovskay, The construction of marine facilities in the Arctic: a tutorial (Polytechnical Institute, Saint Petersburg, 2016)

21. M. Kelleher, J. Jensen, P. Kastrup, M. Hodder, 22nd Australasian Coastal and Ocean Engineering Conf. and the 15th Australasian Port and Harbour Conf. 462-468 (Engineers Australia and IPENZ, Auckland, New Zealand, 2015)

22. E.I. Suslikov, V.I. Morozov, B.A. Pinegin, Port hydraulic engineering construction in the Ob-Irtysh basin. Main design solutions of hydraulic structures and areas for their improvement (OJSC "Sibrechproekt", Novosibirsk, 2002)

23. P. Garibin, E. Ol'khovik, I. Rastorguev. E3S Web of Conferences 33, 03064 (2018) doi:10.1051/e3sconf/20183303064 